\title{
Fiberoptic-Coupled Spectrofluorometer with Array Detection as a Process Analytical Chemistry Tool for Continuous Flow Monitoring of Fluoroquinolone Antibiotics
}

\author{
Nader Shokoufi $\left({ }^{1},{ }^{1}\right.$ Maryam Vosough, ${ }^{1}$ Mona Rahimzadegan-Asl, ${ }^{1}$ Atefeh Abbasi-Ahd, ${ }^{1}$ \\ and Mahsa Khatibeghdami \\ ${ }^{1}$ Analytical Instrumentation and Spectroscopy Laboratory, Department of Green Technologies, \\ Chemistry \& Chemical Engineering Research Center of Iran, Tehran 14968-13151, Iran \\ ${ }^{2}$ Cancer Center, University of Illinois, Chicago, IL 60612, USA
}

Correspondence should be addressed to Nader Shokoufi; n.shokoufi@ccerci.ac.ir

Received 11 July 2019; Revised 28 November 2019; Accepted 8 January 2020; Published 7 February 2020

Academic Editor: Charles L. Wilkins

Copyright (c) 2020 Nader Shokoufi et al. This is an open access article distributed under the Creative Commons Attribution License, which permits unrestricted use, distribution, and reproduction in any medium, provided the original work is properly cited.

\begin{abstract}
Nowadays, there is an increasing need for sensitive real-time measurements of various analytes and monitoring of industrial products and environmental processes. Herein, we describe a fluorescence spectrometer in continuous flow mode in which the sample is fed to the flow cell using a peristaltic pump. The excitation beam is introduced to the sample chamber by an optical fiber. The fluorescence emitted upon excitation is collected at the right angle using another optical fiber and then transmitted to the fluorescence spectrometer which utilizes an array detector. The array detection, as a key factor in process analytical chemistry, made the fluorescence spectrometer suited for multiwavelength detection of the fluorescence spectrum of the analytes. After optimization of the experimental parameters, the system has been successfully employed for sensitive determination of four fluoroquinolone antibiotics such as ciprofloxacin, ofloxacin, levofloxacin, and moxifloxacin. The linear dynamic ranges of four fluoroquinolones were between 0.25 and $20 \mu \mathrm{g} \cdot \mathrm{mL}^{-1}$, and the detection limit of the method for ciprofloxacin, ofloxacin, levofloxacin, and moxifloxacin were $81,36,35$, and $93 \mathrm{ng} \cdot \mathrm{mL}^{-1}$, respectively. Finally, the proposed system is carried out for determination of fluoroquinolones in some pharmaceutical formulations.
\end{abstract}

\section{Introduction}

The Process Analytical Chemistry (PAC) is the application of analytical chemistry using specific techniques, algorithms, and sampling equipment which addresses the problems of chemical processes $[1,2]$. In traditional analytical process, sampling was carried out manually, and then these samples were transferred to quality control laboratories [3]. Sometimes this approach was harmful, dangerous and also expensive, and ultimately did not result in good data in terms of accuracy. Also, in terms of time, it could not adequately demonstrate the process conditions. The delay in the analysis results prevented real-time and online analysis. Over time, it became clear that real-time measurements would provide time information in a process, so instead of offline measurements, continuous flow analytical devices were applied for online monitoring [4-8]. In continuous monitoring, direct connection of the sampling system, and the system itself, enables us to automate and control the collection of data and their analysis [5, 9]. The Process Analytical Technology (PAT) $[10,11]$ was defined in 2004 by the Food and Drug Administration (FDA) to support innovation in the industry quality control. PAT has many applications in the pharmaceutical and antibiotics manufacturing [12-25], chemical [26, 27], petrochemical [28], and food industries [29-33]. In addition, there are many recent progress in realtime monitoring of cultivations in bioreactors and cell culture process [34-41], fermentation [42, 43] and biological 
process [44], and electrochemical $[45,46]$ and protein purification [47]. Using PAT enables us to get a deeper understanding of the process. The process knowledge can increase the product integrity and production efficiency while it can reduce impurities and undesirable crops and costs which all lead to cost reduction eventually. By having additional information and knowledge about a process, it is possible to understand the parameters that influence the process and its quality control $[15,48]$.

Fluoroquinolones are among the most important antibacterial agents which were developed in the 80s and are now widely used in medicine and veterinary medicine [49]. Therefore, several analytical procedure has been reported for determination of fluoroquinolones including high-performance liquid chromatography (HPLC) [50-62], spectrophotometry [63], fluorimetry [64-73], flow-injection based on chemiluminescence [74-76], chemiluminescence [77, 78], terbium-sensitized luminescence [79], solid-phase spectrofluorimetry $[80,81]$, capillary electrophoresis [82, 83], convenient magnetic solid-phase extraction procedure coupled with capillary electrophoresis [84], solid-phase microextraction coupled with liquid chromatography-tandem mass spectrometry [85], liquid-liquid microextraction [86], polarography [87], and colorimetry [88] But, there is no report for application of PAT or PAC for online monitoring of fluoroquinolones.

Hence, the main objective of this study is to develop a method for chemical analysis and monitoring of four fluoroquinolones (ciprofloxacin, ofloxacin, levofloxacin, and moxifloxacin) at continuous flow mode using a fiberoptic fluorescence array detecting system in pharmaceutical products.

\section{Materials and Methods}

2.1. Chemicals. Fluoranthene (a poly-aromatic hydrocarbon composition) with a purity of $98 \%$ was purchased from Sigma-Aldrich (St. Louis, MO). Spectroscopy-grade methanol was obtained from Merck (Darmstadt, Germany). Deionized water was produced by Millipore device (France). Active pharmaceutical ingredients (API) of the antibiotics ciprofloxacin, ofloxacin, levofloxacin, and moxifloxacin were commercially purchased from both Droupakhsh and Hakim Pharmaceutical Companies (Iran). The drug samples including intravenous infusion of $0.2 \%$ ciprofloxacin (Samen Mashhad Pharmaceuticals Company, Iran), ocular drop of 0.3\% ciprofloxacin (Ciplex from Sina Darou Company, Iran), $200 \mathrm{mg}$ ciprofloxacin tablet (Tehran Pharmaceuticals Company, Iran), ocular drop of $0.5 \%$ of levofloxacin (Oftaquix from Santen Pharmaceuticals Company in Finland), $500 \mathrm{mg}$ tablet of levofloxacin (Tavanex) (Abidi Pharmaceutical Company, Iran) and $200 \mathrm{mg}$ tablet of ofloxacin (Rouz-Darou Pharmaceutical Company, Iran) were also commercially purchased.

2.2. Apparatus. The florescence spectra were obtained by Array spectrophotometer model USB4000-FL with the light source of deuterium lamp model DH-2000 series and xenon model PX-2 (Ocean Optics Company, USA). The flow cell model FIA-SMA-FL-ULT series and the optical fibers model P600-2-SR were also from Ocean Optics (USA). The utilized optical fibers cover a wavelength region of $300^{-1} 100 \mathrm{~nm}$ and have a core diameter of $600 \mu \mathrm{m}$. The flow adjusted by Peristaltic pump model $\mathrm{BT} 100^{-1} \mathrm{~F}$ (Longer Precision Pump, China).

2.3. General Procedure. The stock solution of $1000 \mu \mathrm{g} \cdot \mathrm{mL}^{-1}$ of four standard samples of antibiotics, including ciprofloxacin, ofloxacin, levofloxacin and moxifloxacin were separately prepared in $2: 1$ ratio of methanol/deionized water. Then, the dilution solutions of each were daily made and at continuous flow mode fed to the flow cell and detected by a fiber-optic fluorescence arrays system.

\subsection{Fluorescence Array System in Continuous Flow Mode.} In continuous flow monitoring, the flow of sample is continuously fed into a fluorescence flow cell by a peristaltic pump. Two fiberoptic probes were utilized to direct the light from light source to the flow cell and the fluorescence array from flow cell through the detector. Data are recorded and displayed on the computer software. The utilized laboratory set is presented in Figure 1.

2.5. Procedure for Pharmaceutical Samples. In order to validate the optimized method, the recovery value of different forms of commercial pharmaceutical samples of ciprofloxacin, ofloxacin, and levofloxacin were investigated. The pharmaceutical samples were included intravenous infusion of $0.2 \%$ ciprofloxacin, ocular drops of $3.8 \%$ ciprofloxacin, $200 \mathrm{mg}$ ciprofloxacin tablet, $0.5 \%$ ocular droplet of levofloxacin, a $500 \mathrm{mg}$ tablet of levofloxacin, and $200 \mathrm{mg}$ ofloxacin tablet.

2.6. Preparation of Ciprofloxacin and Levofloxacin Solutions. For the analysis of ciprofloxacin, a stock solution of $2 \mu \mathrm{g} \cdot \mathrm{mL}^{-1}$ was prepared from $0.2 \%$ intravenous infusion of that. In order to evaluate accuracy of the method, other quantities of standard ciprofloxacin were added to the sample solution for recovery tests. All measurements repeated five times. The same procedure of sample preparation was repeated for measuring eye drops of ciprofloxacin $0.3 \%$ and levofloxacin $0.5 \%$.

\subsection{Preparation of Ciprofloxacin and Ofloxacin Solutions.} For the analysis of ciprofloxacin samples, appropriate amount of ciprofloxacin tablets were weighed and transferred to a $100 \mathrm{~mL}$ container to form a stock solution of $1000 \mu \mathrm{g} \cdot \mathrm{mL}^{-1}$. Then, it was placed in an ultrasonic bath for 20 minutes. It was filtered with 0.22 micron membrane filters. Finally, it was diluted within the concentration range of the calibration curve and detected. Then, other quantities of standard ciprofloxacin were added to the sample solution for recovery tests. All measurements repeated five times.

The same procedure of sample preparation was repeated for measuring ofloxacin tablets. 


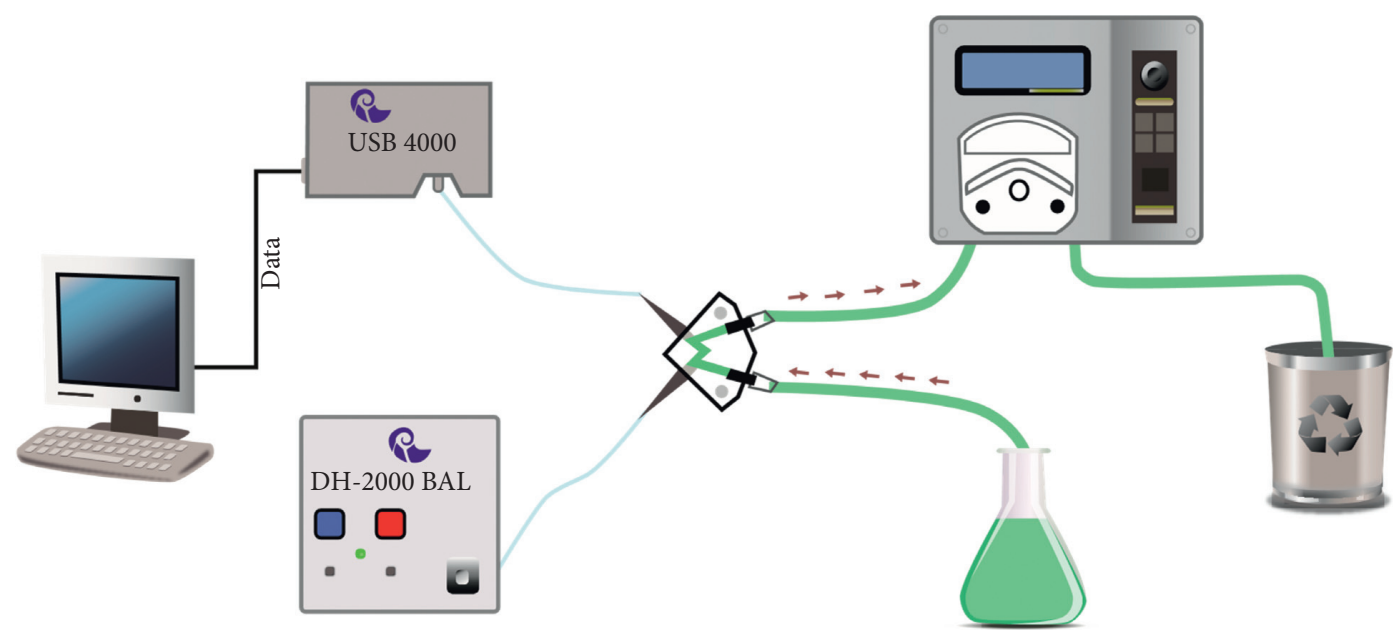

FIGURE 1: Experimental setup for continuous flow measurements using spectrofluorometric fiberoptic array.

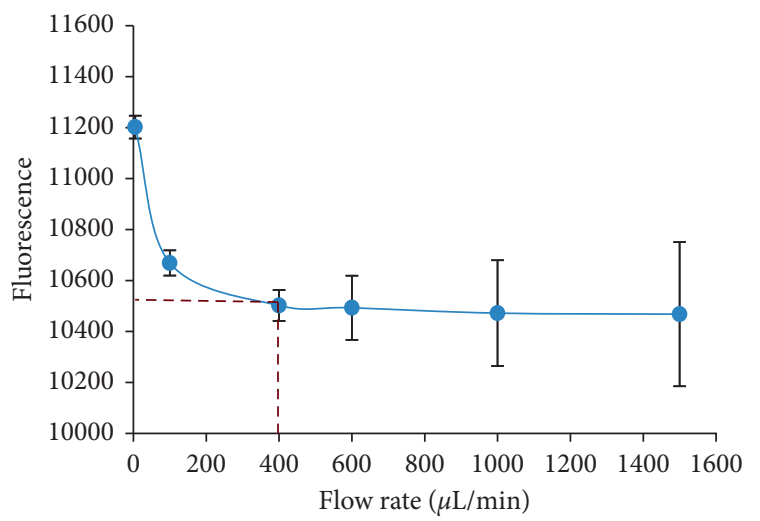

(a)

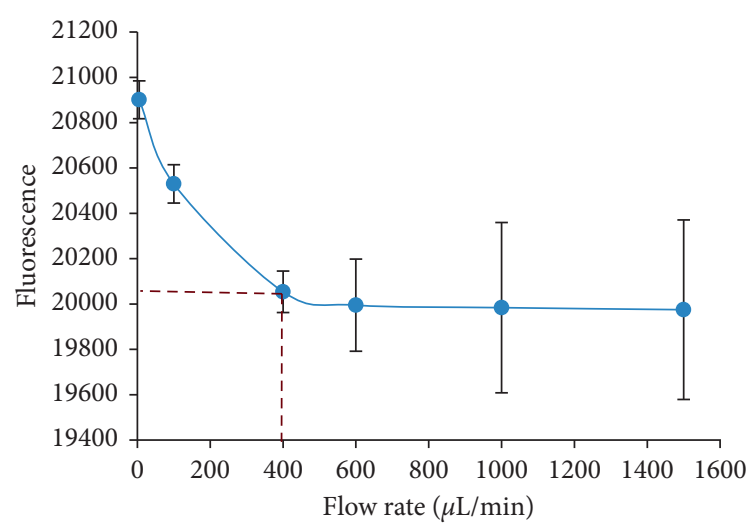

(c)

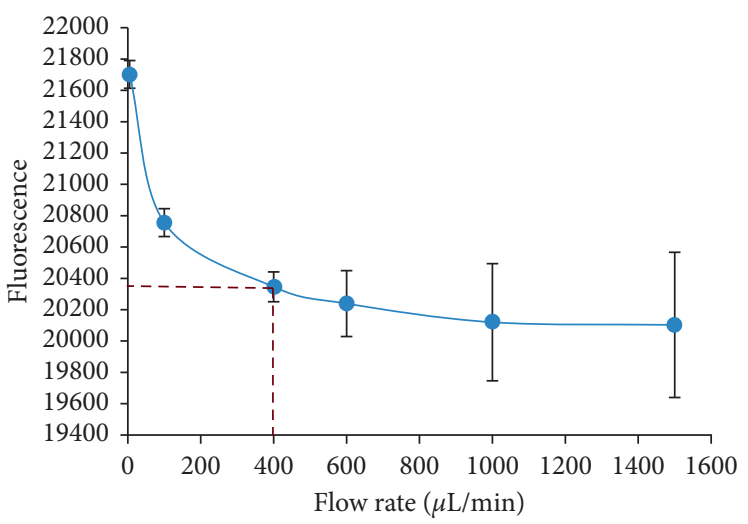

(b)

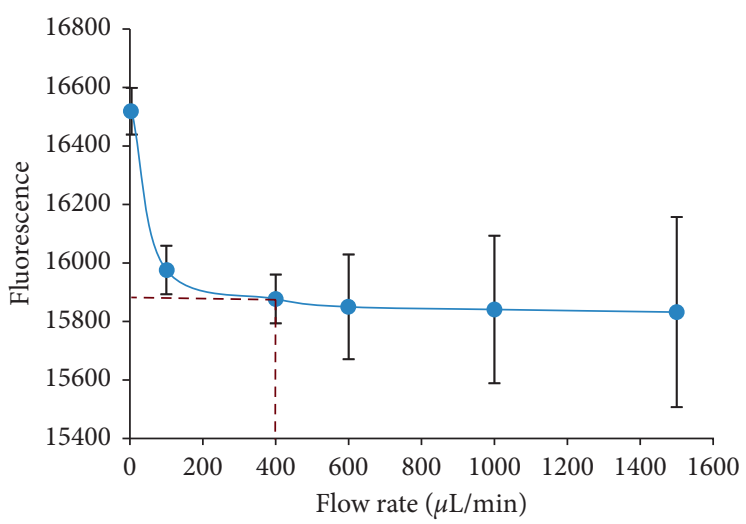

(d)

Figure 2: Effect of flow rate: (a) ciprofloxacin, (b) ofloxacin, (c) levofloxacin, and (d) moxifloxacin. Condition: concentration $5 \mu \mathrm{g} \cdot \mathrm{mL}^{-1}$; integration time: $600 \mathrm{mS}$.

\section{Results and Discussion}

3.1. Process Optimization. Optimization process was performed by optimizing flow velocity and integration time.

3.2. Effect of Flow Rate. The flow rates of the sample were optimized in the range of $5-1500 \mu \mathrm{L} \cdot \mathrm{min}^{-1}$ (Figure 2). The signal slightly decreased following the increase of the flow rate, it was considered that for the flow rate upper than $400 \mu \mathrm{L} \cdot \mathrm{min}^{-1}$, the obtained fluorescence spectra were unstable.

So, the flow rate of $400 \mu \mathrm{L} \cdot \mathrm{min}^{-1}$ was chosen for the best conformity with the signal stability and throughput of the sample. 


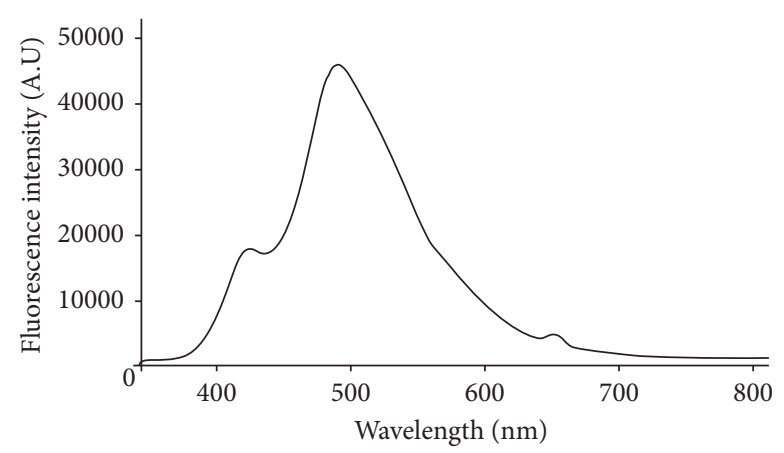

FIGURE 3: Optimization of integration time for levofloxacin. Condition: concentration $25 \mu \mathrm{g} \cdot \mathrm{mL}^{-1}$; integration time: $600 \mathrm{mS}$.
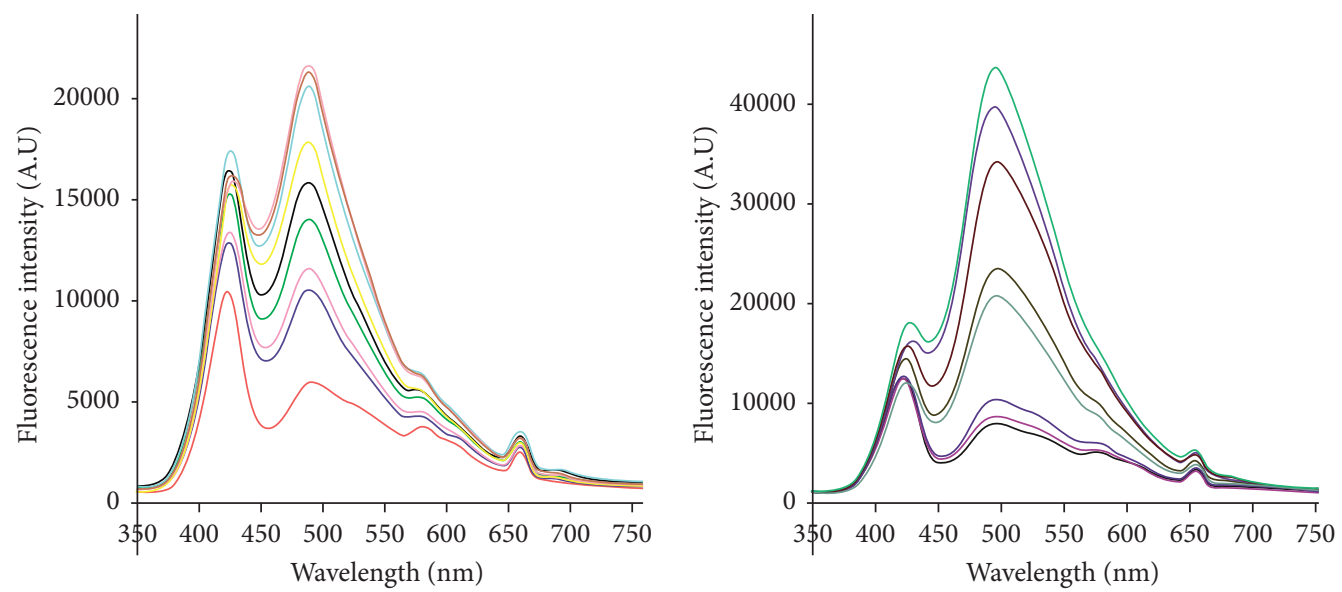

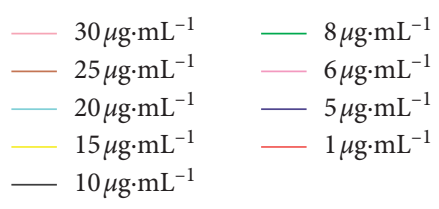

(a)
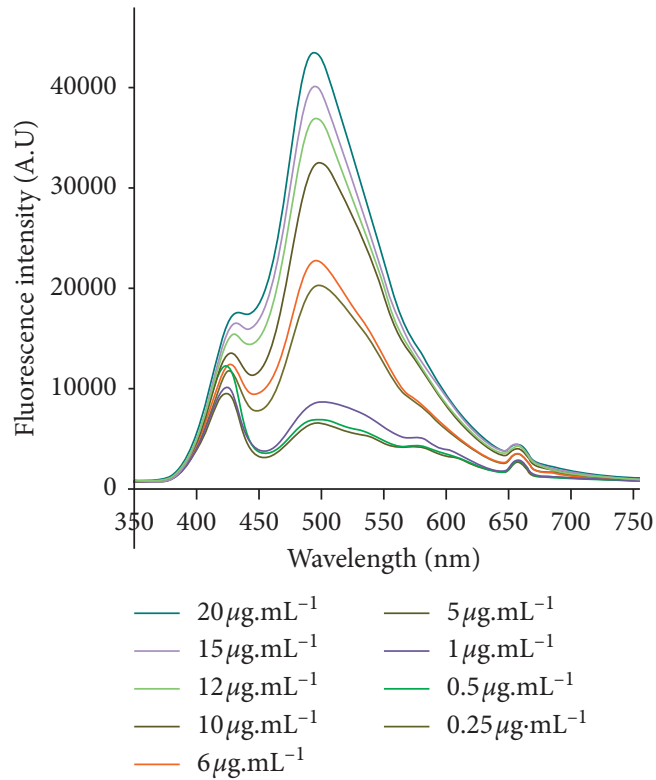

(c)

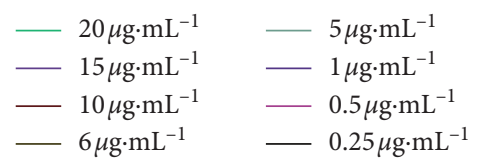

(b)
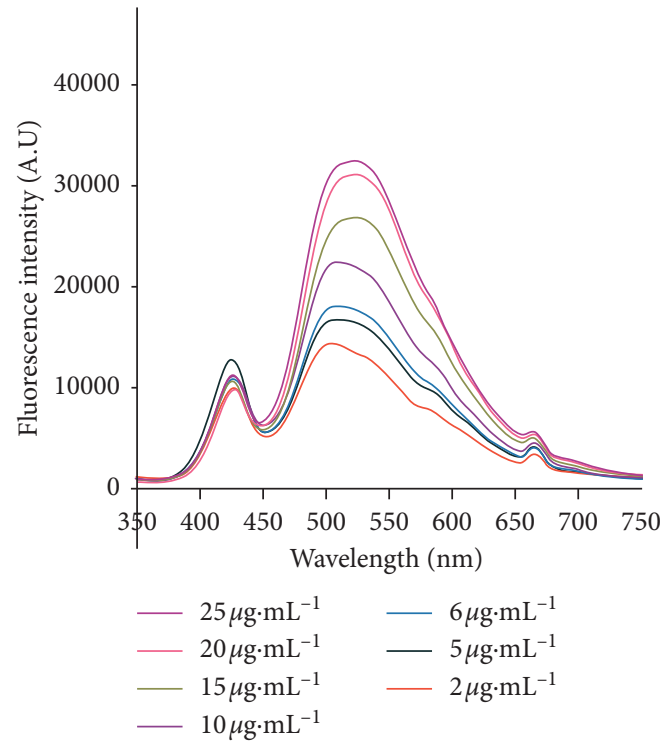

(d)

Figure 4: Fluorescence spectra of standard solutions: (a) ciprofloxacin, (b) ofloxacin, (c) levofloxacin, and (d) moxifloxacin. Condition: flow rate; $400 \mu \mathrm{L} \cdot \mathrm{min}^{-1}$; integration time: $600 \mathrm{mS}$. 


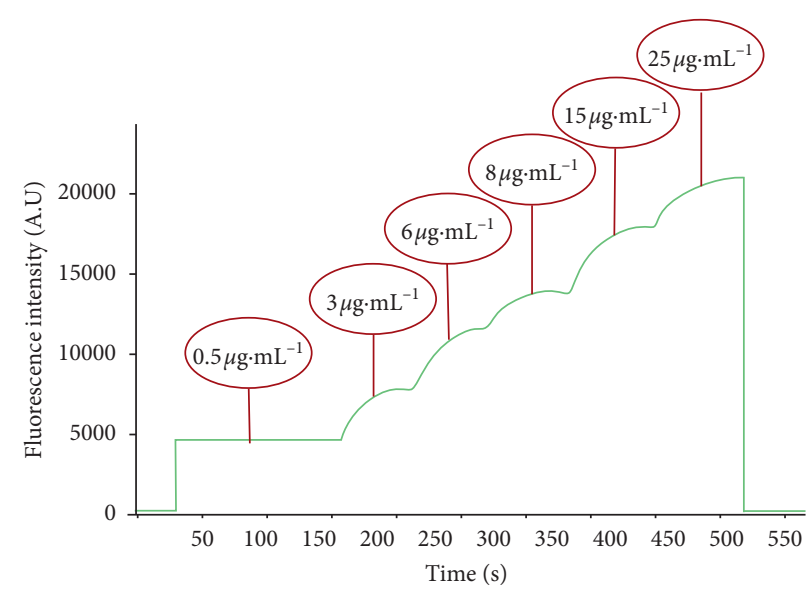

(a)

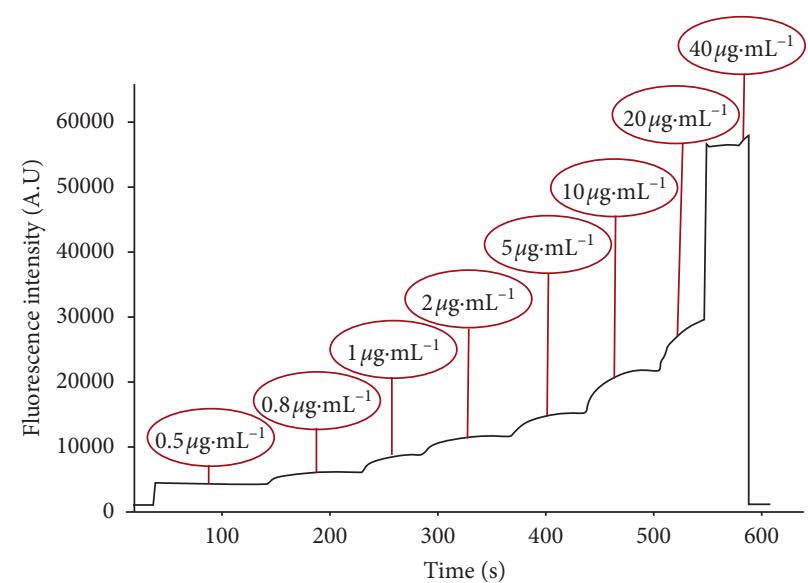

(b)

FIGURE 5: Fluorescence intensity vs. time: (a) ciprofloxacin, condition: flow rate: $400 \mu \mathrm{L} \cdot \mathrm{min}^{-1}$, integration time: $600 \mathrm{mS}, \lambda_{\max }: 489 \mathrm{~nm}$, and concentration range: $0.5-25 \mu \mathrm{g} \cdot \mathrm{mL}^{-1}$; (b) moxifloxacin, condition: flow rate: $400 \mu \mathrm{L} \cdot \mathrm{min}^{-1}$, integration time: $600 \mathrm{mS}, \lambda_{\max }: 512 \mathrm{~nm}$, and concentration range: $0.5-40 \mu \mathrm{g} \cdot \mathrm{mL}^{-1}$.

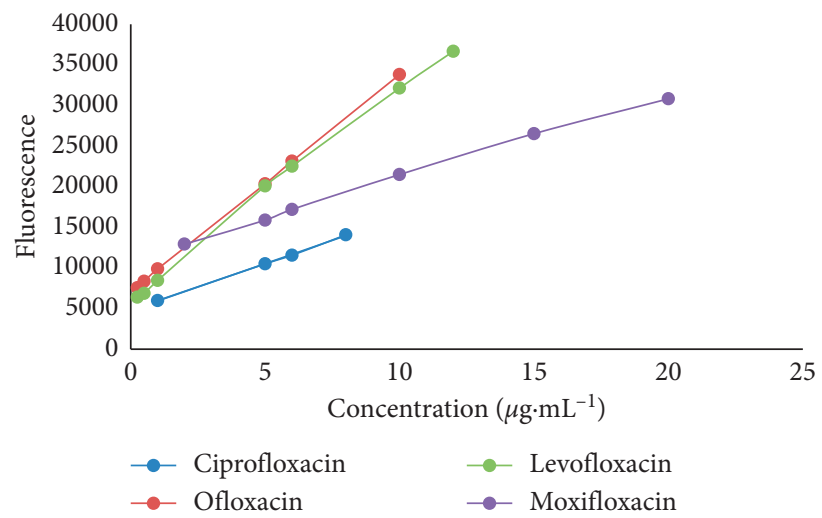

FIGURE 6: Calibration curve of standard fluoroquinolones. Condition: flow rate, $400 \mu \mathrm{L} \cdot \mathrm{min}^{-1}$; integration time: $600 \mathrm{mS}$.

3.3. Optimization of Integration Time. The integration time of the spectrometer (analogous to the shutter speed) was also optimized. The higher the integration time, the longer the detector monitors the incoming photons. For too low intensity, the value increased and vice versa. For the $25 \mathrm{mg} \cdot \mathrm{mL}^{-1}$ of levofloxacin standard solution, with the integration time of $600 \mathrm{mS}$, the maximum intensity 45118.7 was achieved (Figure 3).

3.4. Characteristics of Emission Spectrum. The emission spectrums of various standard solutions of ciprofloxacin, ofloxacin, levofloxacin, moxifloxacin were recorded at the optimized conditions (Figure 4).

To demonstrate the capability of the method for continuous monitoring, $1 \mathrm{cc}$ of standard solutions of ciprofloxacin and moxifloxacin from low concentration to high concentration were added to the flow cell, respectively, and changes of fluorescence intensity vs. time was monitored. As depicted in Figure 5, by increasing the concentration of ciprofloxacin and moxifloxacin the fluorescence intensity rises instantly.
3.5. Analytical Performances. Series concentrations of four antibiotics including ciprofloxacin, ofloxacin, levofloxacin, and moxifloxacin were used for drawing the calibration curves. A calibration graph of florescence intensity versus the sample concentration is presented in Figure 6.

The linear relationship, detection limit, and relative standard deviation of each are presented in Table 1.

In comparison with the other methods for fluoroquinolones determination, despite of simplicity of method, no labelling agent or additive for signal enhancement and monitoring of flowing sample, the proposed method had $\mathrm{ng} \cdot \mathrm{mL}^{-1}$ detection limit which is quite comparable with the most of other reported methods (Table 2).

3.6. Interference Study. To evaluate the selectivity of the developed method for the analysis of pharmaceutical preparations containing ciprofloxacin, the effects of some potential interference compounds (used as additive to pharmaceutical samples) such as fructose, glucose, sucrose, lactose, sorbitol, sodium citrate, magnesium stearate, talc, methyl cellulose, and starch on the efficiency of the 
TABLE 1: The analytical performance of the method.

\begin{tabular}{|c|c|c|c|c|}
\hline Parameter & Moxifloxacin & Levofloxacin & Ofloxacin & Ciprofloxacin \\
\hline$\lambda_{\max }(\mathrm{nm})$ & 525 & 495 & 497 & 489 \\
\hline Linear range $\left(\mu \mathrm{g} \cdot \mathrm{mL}^{-1}\right)$ & $2-20$ & $0.25-12$ & $0.25-10$ & $1-8$ \\
\hline Relative standard deviation* $(n=7 \%)$ & 0.527 & 0.517 & 0.468 & 0.561 \\
\hline Detection limit $\left(\mu \mathrm{g} \cdot \mathrm{mL}^{-1}\right)$ & 0.093 & 0.036 & 0.035 & 0.081 \\
\hline $\mathrm{LOQ}\left(\mu \mathrm{g} \cdot \mathrm{mL}^{-1}\right)$ & 0.308 & 0.1185 & 0.1155 & 0.269 \\
\hline Correlation coefficient & 0.9979 & 0.9972 & 0.9999 & 0.9992 \\
\hline
\end{tabular}

*Concentration: $5 \mu \mathrm{g} \cdot \mathrm{mL}^{-1}$.

TABle 2: Comparison of this method with other reported methods for determination of fluoroquinolones.

\begin{tabular}{lcc}
\hline Method & Linear range $\left(\mu \mathrm{g} \cdot \mathrm{mL}^{-1}\right)$ & ${\text { Detection limit }\left(\mu \mathrm{g} \cdot \mathrm{mL}^{-1}\right)}$ \\
\hline Spectrofluorometric [65] & $0.02-2.2$ & $0.006-0.016$ \\
HPLC-UV [89] & 0.15 to 5 & $0.04-0.08$ \\
HPLC [57] & $0.003-1.3$ & 0.001 \\
HPLC-fluorescence [90] & $0.005-0.1$ & $0.0005-0.005$ \\
Capillary electrophoresis [83] & $5-20$ & 1.1 and 2.4 \\
Chemiluminescence [77] & $1.98 \times 10^{-9}$ & $0.003-7$ \\
HPLC-PDA [91] & $0.1-10$ & 0.03 \\
Spectrophotometric [72] & $0.5-25$ & 0.084 \\
HPLC [92] & $0.0005-1$ & 0.00007 \\
This method & $0.25-20$ & $0.035-0.093$ \\
\hline
\end{tabular}

TABLE 3: Effect of some foreign interference compounds.

\begin{tabular}{lc}
\hline Tolerance limit [foreign substance]/[CIP] & Foreign substance added \\
\hline 80 & Fructose, glucose, sucrose, lactose, sorbitol, sodium citrate, methyl cellulose \\
50 & Magnesium stearate \\
40 & Talc, starch \\
\hline
\end{tabular}

TABle 4: Determination of ciprofloxacin, ofloxacin, and levofloxacin in pharmaceutical formulations.

\begin{tabular}{|c|c|c|c|c|c|c|c|c|}
\hline Analytes & Tissue & $\begin{array}{c}\text { Original } \\
\left(\mathrm{mg} \cdot \mathrm{mL}^{-1}\right)\end{array}$ & $\begin{array}{c}\text { Found } \\
\left(\mathrm{mg} \cdot \mathrm{mL}^{-1}\right)\end{array}$ & $\begin{array}{c}\text { RSD } \\
(n=5 \%)\end{array}$ & $\begin{array}{c}\text { Content } \\
\left(\mu \mathrm{g} \cdot \mathrm{mL}^{-1}\right)\end{array}$ & $\begin{array}{c}\text { Added } \\
\left(\mu \mathrm{g} \cdot \mathrm{mL}^{-1}\right)\end{array}$ & $\begin{array}{c}\text { Found } \\
\left(\mu \mathrm{g} \cdot \mathrm{mL}^{-1}\right)\end{array}$ & $\begin{array}{c}\text { Recovery } \\
(n=5 \%)\end{array}$ \\
\hline \multirow{3}{*}{ CIP } & \multirow{3}{*}{ Infusion } & \multirow{3}{*}{2} & $1.99 \pm 0.003$ & 1.91 & $0.04 \pm 1.99$ & 1 & $0.05 \pm 3.01$ & $102 \pm 3$ \\
\hline & & & $1.92 \pm 0.036$ & 1.34 & $0.03 \pm 1.92$ & 3 & $0.19 \pm 5.01$ & $103 \pm 2$ \\
\hline & & & $1.96 \pm 0.016$ & 1.06 & $1.96 \pm 0.02$ & 5 & $0.09 \pm 6.97$ & $100 \pm 2$ \\
\hline \multirow{3}{*}{ CIP } & \multirow{3}{*}{$\begin{array}{l}\text { Eye } \\
\text { drop }\end{array}$} & \multirow{3}{*}{3} & $2.91 \pm 0.028$ & 8.80 & $0.17 \pm 1.94$ & 1 & $0.23 \pm 3.02$ & $108 \pm 4$ \\
\hline & & & $2.93 \pm 0.054$ & 7.96 & $0.16 \pm 1.95$ & 3 & $0.14 \pm 5.03$ & $102 \pm 3$ \\
\hline & & & $2.98 \pm 0.006$ & 5.68 & $0.11 \pm 1.98$ & 5 & $0.08 \pm 7.01$ & $100 \pm 3$ \\
\hline \multirow{3}{*}{ CIP } & \multirow{3}{*}{ Tablet } & \multirow{3}{*}{2.5} & $2.47 \pm 0.009$ & 7.06 & $0.14 \pm 1.98$ & 1 & $0.23 \pm 2.96$ & $98 \pm 4$ \\
\hline & & & $2.47 \pm 0.010$ & 4.34 & $0.09 \pm 1.97$ & 3 & $0.17 \pm 5.10$ & $104 \pm 5$ \\
\hline & & & $2.41 \pm 0.03$ & 6.71 & $0.13 \pm 1.93$ & 5 & $0.21 \pm 6.89$ & $99 \pm 4$ \\
\hline \multirow{3}{*}{ OFLX } & \multirow{3}{*}{ Tablet } & \multirow{3}{*}{2} & $1.98 \pm 0.006$ & 7.24 & $0.14 \pm 1.98$ & 1 & $0.15 \pm 2.97$ & $98 \pm 4$ \\
\hline & & & $1.91 \pm 0.043$ & 7.63 & $0.15 \pm 1.91$ & 3 & $0.19 \pm 5.06$ & $104 \pm 5$ \\
\hline & & & $1.95 \pm 0.022$ & 6.24 & $0.12 \pm 1.95$ & 5 & $0.19 \pm 6.98$ & $99 \pm 4$ \\
\hline \multirow{3}{*}{ Levo } & \multirow{3}{*}{ Tablet } & \multirow{3}{*}{5} & $5.37 \pm 0.075$ & 5.81 & $0.13 \pm 2.15$ & 1 & $0.35 \pm 3.17$ & $102 \pm 4$ \\
\hline & & & $5.32 \pm 0.064$ & 5.35 & $0.11 \pm 2.12$ & 3 & $0.29 \pm 5.21$ & $103 \pm 4$ \\
\hline & & & $5.17 \pm 0.034$ & 7.39 & $0.15 \pm 2.06$ & 5 & $0.12 \pm 7.17$ & $102 \pm 3$ \\
\hline \multirow{3}{*}{ Levo } & \multirow{3}{*}{$\begin{array}{l}\text { Eye } \\
\text { drop }\end{array}$} & \multirow{3}{*}{5} & $5.38 \pm 0.077$ & 5.01 & $0.11 \pm 2.15$ & 1 & $0.26 \pm 3.13$ & $98 \pm 4$ \\
\hline & & & $5.18 \pm 0.036$ & 5.83 & $0.12 \pm 2.07$ & 3 & $0.16 \pm 5.11$ & $101 \pm 4$ \\
\hline & & & $5.23 \pm 0.046$ & 7.54 & $0.16 \pm 2.09$ & 5 & $0.17 \pm 7.08$ & $100 \pm 4$ \\
\hline
\end{tabular}

presented method were studied. A standard sample solution of ciprofloxacin $\left(5 \mu \mathrm{g} \cdot \mathrm{mL}^{-1}\right)$ was analysed in the presence of the extra amount of coexisting substances. A compound was considered as noninterfering if the variation of its signal was less than $\pm 5 \%$ in comparison with the signal in the absence of that. Table 3 shows the results obtained. The results indicated that there were no significant interferences produced by these excipients 
substances on the proposed method for the determination of ciprofloxacin.

3.7. Measurements in Pharmaceutical Formulation. In order to evaluate the applicability of the optimized method for determination of fluoroquinolones, the recovery percent of ciprofloxacin, ofloxacin, and levofloxacin in pharmaceutical samples were investigated. The obtained results for commercial pharmaceutical samples are summarized in Table 3. The results show the potential of the developed method for the measurement of real samples (Table 4).

\section{Conclusions}

In this study, we have proposed a simple and sensitive method for quantitative measurement of fluoroquinolones medicines. The combination of flow system and array spectrofluorometric provides the ability to apply PAC for multiwavelength online monitoring of fluoroquinolones. The developed method was successfully utilized for analysis of ciprofloxacin, ofloxacin, levofloxacin, and moxifloxacin in low concentration range with detection limit of $35-93 \mathrm{ng} \cdot \mathrm{mL}^{-1}$.

In addition to the fast detection time and automation, acceptable accuracy, and good reproducibility, the proposed method was used to measure fluoroquinolones in six forms of commercial pharmaceutical formulation as well and the obtained results showed the capability of method to be applied for online industrial analysis of real samples.

\section{Data Availability}

The data used to support the findings of this study are available from the corresponding author upon request.

\section{Conflicts of Interest}

The authors declare that they have no conflicts of interest.

\section{Acknowledgments}

The authors are grateful to the support from Chemistry and Chemical Engineering Research Centre of Iran (CCERCI).

\section{References}

[1] J. Workman Jr., B. Lavine, R. Chrisman, and M. Koch, "Process analytical chemistry," Analytical Chemistry, vol. 83, no. 12, pp. 4557-4578, 2011.

[2] K.-H. Koch, Process Analytical Chemistry, Springer, Berlin, Germany, 1999.

[3] A. R. De Monchy, A. R. Forster, J. R. Arretteig, L. Le, and S. N. Deming, "Expert systems for the analytical laboratory," Analytical Chemistry, vol. 60, no. 23, pp. 1355A-1361A, 1988.

[4] J. Workman, D. J. Veltkamp, S. Doherty et al., "Process analytical chemistry," Analytical Chemistry, vol. 71, no. 12, pp. 121-180, 1999.

[5] J. Workman, M. Koch, and D. J. Veltkamp, "Process analytical chemistry," Analytical Chemistry, vol. 75, no. 12, pp. 28592876, 2003.
[6] L. C. Clark Jr. and C. Lyons, "Electrode systems for continuous monitoring in cardiovascular surgery," Annals of the New York Academy of Sciences, vol. 102, no. 1, pp. 29-45, 1962.

[7] N. Bratanow, K. Polk, R. Bland, H. B. Kram, T.-S. Lee, and W. C. Shoemaker, "Continuous polarographic monitoring of intra-arterial oxygen in the perioperative period," Critical Care Medicine, vol. 13, no. 10, pp. 859-860, 1985.

[8] H. B. Cummings, J. R. Boyle, and B. W. Arp, "Continuous, online monitoring of freestanding, oil-filled current transformers to predict imminent failure," IEEE Transactions on Power Delivery, vol. 3, no. 4, pp. 1776-1783, 1988.

[9] J. Miller and J. C. Miller, Statistics and Chemometrics for Analytical Chemistry, Pearson Education, London, UK, 2018.

[10] S. Scanlon, "Development of a multi-parameter sensing system for process analytical technology application in the food and beverage industry," $\mathrm{Ph}$. D. thesis, University College Cork, Cork, Ireland, 2018.

[11] L. Manley, J. Hilden, P. Valero, and T. Kramer, "Tablet compression force as a process analytical technology (PAT): $100 \%$ inspection and control of tablet weight uniformity," Journal of Pharmaceutical Sciences, vol. 108, no. 1, pp. 485493, 2019.

[12] D. M. Parikh, Handbook of Pharmaceutical Granulation Technology, CRC Press, Boca Raton, FL, USA, 2016.

[13] K. A. Esmonde-White, M. Cuellar, C. Uerpmann, B. Lenain, and I. R. Lewis, "Raman spectroscopy as a process analytical technology for pharmaceutical manufacturing and bioprocessing," Analytical and Bioanalytical Chemistry, vol. 409, no. 3, pp. 637-649, 2017.

[14] J. M. Vargas, S. Nielsen, V. Cárdenas et al., "Process analytical technology in continuous manufacturing of a commercial pharmaceutical product," International Journal of Pharmaceutics, vol. 538, no. 1-2, pp. 167-178, 2018.

[15] K. A. Bakeev, Process Analytical Technology: Spectroscopic Tools and Implementation Strategies for the Chemical and Pharmaceutical Industries, John Wiley \& Sons, Hoboken, NJ, USA, 2010.

[16] N. Bostijn, W. Dhondt, C. Vervaet, and T. De Beer, "PATbased batch statistical process control of a manufacturing process for a pharmaceutical ointment," European Journal of Pharmaceutical Sciences, vol. 136, Article ID 104946, 2019.

[17] R. Liu, Q. Sun, T. Hu et al., "Multi-parameters monitoring during traditional Chinese medicine concentration process with near infrared spectroscopy and chemometrics," Spectrochimica Acta Part A: Molecular and Biomolecular Spectroscopy, vol. 192, pp. 75-81, 2018.

[18] P. Pawar, S. Talwar, D. Reddy et al., “A "large-N" content uniformity process analytical technology (PAT) method for phenytoin sodium tablets," Journal of Pharmaceutical Sciences, vol. 108, no. 1, pp. 494-505, 2019.

[19] M. Foroughi-Dahr, R. Sotudeh-Gharebagh, and N. Mostoufi, "Development of a PAT tool for monitoring the Wurster coater performance," International Journal of Pharmaceutics, vol. 561, pp. 171-186, 2019.

[20] D. Fissore and T. McCoy, "Freeze-drying and process analytical technology for pharmaceuticals," Frontiers in Chemistry, vol. 6, p. 622, 2018.

[21] M. Dumarey, M. Hermanto, C. Airiau et al., "Advances in continuous active pharmaceutical ingredient (API) manufacturing: real-time monitoring using multivariate tools," Journal of Pharmaceutical Innovation, vol. 14, no. 4, pp. 359-372, 2019.

[22] A. Balogh, A. Domokos, B. Farkas et al., "Continuous end-toend production of solid drug dosage forms: coupling flow 
synthesis and formulation by electrospinning," Chemical Engineering Journal, vol. 350, pp. 290-299, 2018.

[23] D. Brouckaert, L. De Meyer, B. Vanbillemont et al., "Potential of near-infrared chemical imaging as process analytical technology tool for continuous freeze-drying," Analytical Chemistry, vol. 90, no. 7, pp. 4354-4362, 2018.

[24] Z. Rahman, A. Siddiqui, and M. A. Khan, "Characterization of a nonribosomal peptide antibiotic solid dispersion formulation by process analytical technologies sensors," Journal of Pharmaceutical Sciences, vol. 102, no. 12, pp. 4337-4346, 2013.

[25] J. A. Lopes, P. F. Costa, T. P. Alves, and J. C. Menezes, "Chemometrics in bioprocess engineering: process analytical technology (PAT) applications," Chemometrics and Intelligent Laboratory Systems, vol. 74, no. 2, pp. 269-275, 2004.

[26] X. Y. Lawrence, R. A. Lionberger, A. S. Raw et al., "Applications of process analytical technology to crystallization processes," Advanced Drug Delivery Reviews, vol. 56, no. 3, pp. 349-369, 2004.

[27] F. Tahir, E. Mercer, I. Lowdon, and D. Lovett, "Advanced process control and monitoring of a continuous flow microreactor," Control Engineering Practice, vol. 77, pp. 225-234, 2018.

[28] H. C. Struthers, F. M. Zehentbauer, E. Ono-Sorhue, and J. Kiefer, "Chemical composition monitoring in a batch distillation process using Raman spectroscopy," Industrial \& Engineering Chemistry Research, vol. 50, no. 22, pp. 1282412830, 2011.

[29] A. Gowen, C. Odonnell, P. Cullen, G. Downey, and J. Frias, "Hyperspectral imaging-an emerging process analytical tool for food quality and safety control," Trends in Food Science \& Technology, vol. 18, no. 12, pp. 590-598, 2007.

[30] F. van den Berg, C. B. Lyndgaard, K. M. Sørensen, and S. B. Engelsen, "Process analytical technology in the food industry," Trends in Food Science \& Technology, vol. 31, no. 1, pp. 27-35, 2013.

[31] C. P. O’Donnell, C. Fagan, and P. J. Cullen, Process Analytical Technology for the Food Industry, Springer, Berlin, Germany, 2014.

[32] S. Grassi and C. Alamprese, "Advances in NIR spectroscopy applied to process analytical technology in food industries," Current Opinion in Food Science, vol. 22, pp. 17-21, 2018.

[33] B. Panikuttira, N. O’Shea, J. T. Tobin, B. K. Tiwari, and C. P. O’Donnell, "Process analytical technology for cheese manufacture," International Journal of Food Science \& Technology, vol. 53, no. 8, pp. 1803-1815, 2018.

[34] H. Wu, E. Read, M. White et al., "Real time monitoring of bioreactor mAb IgG3 cell culture process dynamics via Fourier transform infrared spectroscopy: implications for enabling cell culture process analytical technology," Frontiers of Chemical Science and Engineering, vol. 9, no. 3, pp. 386-406, 2015.

[35] A. Tulsyan, G. Schorner, H. Khodabandehlou, T. Wang, M. Coufal, and C. Undey, "A machine learning approach to calibrate generic Raman models for real time monitoring of cell culture processes," Biotechnology and Bioengineering, vol. 116, no. 10, pp. 2575-2586, 2019.

[36] D. A. M. Pais, R. M. C. Portela, M. J. T. Carrondo, I. A. Isidro, and P. M. Alves, "Enabling PAT in insect cell bioprocesses: in situ monitoring of recombinant adeno-associated virus production by fluorescence spectroscopy," Biotechnology and Bioengineering, vol. 116, no. 11, pp. 2803-2814, 2019.

[37] T. K. Karakach, A. Dachon, J. Choi, C. Miguez, L. Masson, and B. Tartakovsky, "Fluorescence-based real time monitoring and diagnostics of recombinant Pichia pastoris cultivations in a bioreactor," Biotechnology Progress, vol. 35, no. 2, 2019.

[38] R. M. Santos, P. Kaiser, J. C. Menezes, and A. Peinado, "Improving reliability of Raman spectroscopy for $\mathrm{mAb}$ production by upstream processes during bioprocess development stages," Talanta, vol. 199, pp. 396-406, 2019.

[39] B. Moore, R. Sanford, and A. Zhang, "Case study: the characterization and implementation of dielectric spectroscopy (biocapacitance) for process control in a commercial GMP CHO manufacturing process," Biotechnology Progress, vol. 35, no. 3, p. e2782, 2019.

[40] A. Tulsyan, T. Wang, G. Schorner, H. Khodabandehlou, M. Coufal, and C. Undey, "Automatic real time calibration, assessment, and maintenance of generic Raman models for online monitoring of cell culture processes," Biotechnology and Bioengineering, vol. 117, no. 2, pp. 406-416, 2019.

[41] D. A. Zavala-Ortiz, B. Ebel, M.-Y. Li et al., "Interest of locally weighted regression to overcome nonlinear effects during in situ NIR monitoring of CHO cell culture parameters and antibody glycosylation," Biotechnology Progress, 2019.

[42] S. Goldrick, C. A. Duran-Villalobos, K. Jankauskas et al., "Modern day monitoring and control challenges outlined on an industrial-scale benchmark fermentation process," Computers \& Chemical Engineering, vol. 130, p. 106471, 2019.

[43] J. Roberts, A. Power, J. Chapman, S. Chandra, and D. Cozzolino, "The use of UV-Vis spectroscopy in bioprocess and fermentation monitoring," Fermentation, vol. 4, no. 1, p. 18, 2018.

[44] S. Katla, N. Mohan, S. S. Pavan, U. Pal, and S. Sivaprakasam, "Control of specific growth rate for the enhanced production of human interferon $\alpha 2 b$ in glycoengineered Pichia pastoris: process analytical technology guided approach," Journal of Chemical Technology \& Biotechnology, vol. 94, no. 10, pp. 3111-3123, 2019.

[45] H. Li, J. Somerson, F. Xia, and K. W. Plaxco, "Electrochemical DNA-based sensors for molecular quality control: continuous, real-time melamine detection in flowing whole milk," Analytical Chemistry, vol. 90, no. 18, pp. 10641-10645, 2018.

[46] Y.-W. Wang, Y.-L. Liu, J.-Q. Xu, Y. Qin, and W.-H. Huang, "Stretchable and photocatalytically renewable electrochemical sensor based on sandwich nanonetworks for real-time monitoring of cells," Analytical Chemistry, vol. 90, no. 10, pp. 5977-5981, 2018.

[47] D. G. Sauer, M. Melcher, M. Mosor et al., "Real time monitoring and model based prediction of purity and quantity during a chromatographic capture of fibroblast growth factor 2," Biotechnology and Bioengineering, vol. 116, no. 8, pp. 1999-2009, 2019.

[48] T. Kourti, "The process analytical technology initiative and multivariate process analysis, monitoring and control," $A n$ alytical and Bioanalytical Chemistry, vol. 384, no. 5, pp. 1043-1048, 2006.

[49] A. M. Beltagi, "Determination of the antibiotic drug pefloxacin in bulk form, tablets and human serum using square wave cathodic adsorptive stripping voltammetry," Journal of Pharmaceutical and Biomedical Analysis, vol. 31, no. 6, pp. 1079-1088, 2003.

[50] H. Liang, M. B. Kays, and K. M. Sowinski, "Separation of levofloxacin, ciprofloxacin, gatifloxacin, moxifloxacin, trovafloxacin and cinoxacin by high-performance liquid chromatography: application to levofloxacin determination in human plasma," Journal of Chromatography B, vol. 772, no. 1, pp. 53-63, 2002. 
[51] M. I. R. M. Santoro, N. M. Kassab, A. K. Singh, and E. R. M. Kedor-Hackmam, "Quantitative determination of gatifloxacin, levofloxacin, lomefloxacin and pefloxacin fluoroquinolonic antibiotics in pharmaceutical preparations by high-performance liquid chromatography," Journal of Pharmaceutical and Biomedical Analysis, vol. 40, no. 1, pp. 179184, 2006.

[52] S. Djabarouti, E. Boselli, B. Allaouchiche et al., "Determination of levofloxacin in plasma, bronchoalveolar lavage and bone tissues by high-performance liquid chromatography with ultraviolet detection using a fully automated extraction method," Journal of Chromatography B, vol. 799, no. 1, pp. 165-172, 2004.

[53] Y. H. Xu, D. Li, X. Y. Liu, Y. Z. Li, and J. Lu, "High performance liquid chromatography assay with ultraviolet detection for moxifloxacin: validation and application to a pharmacokinetic study in Chinese volunteers," Journal of Chromatography B, vol. 878, no. 32, pp. 3437-3441, 2010.

[54] T. Lemoine, D. Breilh, D. Ducint et al., "Determination of moxifloxacin (BAY 12-8039) in plasma and lung tissue by high-performance liquid chromatography with ultraviolet detection using a fully automated extraction method with a new polymeric cartridge," Journal of Chromatography B: Biomedical Sciences and Applications, vol. 742, no. 2, pp. 247-254, 2000.

[55] A. Espinosa-Mansilla, A. M. d. 1. Peña, D. G. Gómez, and F. Salinas, "HPLC determination of enoxacin, ciprofloxacin, norfloxacin and ofloxacin with photoinduced fluorimetric (PIF) detection and multiemission scanning," Journal of Chromatography B, vol. 822, no. 1-2, pp. 185-193, 2005.

[56] H. Nguyen, J. Grellet, B. Ba, C. Quentin, and M. Saux, "Simultaneous determination of levofloxacin, gatifloxacin and moxifloxacin in serum by liquid chromatography with column switching," Journal of Chromatography B, vol. 810, no. 1, pp. 77-83, 2004.

[57] A. Labandjurdjevic, M. Jelikicstankov, and P. Djurdjevic, "Optimization and validation of the direct HPLC method for the determination of moxifloxacin in plasma," Journal of Chromatography B, vol. 844, no. 1, pp. 104-111, 2006.

[58] J. Sousa, G. Alves, G. Campos, A. Fortuna, and A. Falcão, "First liquid chromatography method for the simultaneous determination of levofloxacin, pazufloxacin, gatifloxacin, moxifloxacin and trovafloxacin in human plasma," Journal of Chromatography B, vol. 930, pp. 104-111, 2013.

[59] M. A. Neves, G. Silva, N. Brito et al., "Aqueous ultrasoundassisted extraction for the determination of fluoroquinolones in mangrove sediment by high-performance liquid chromatography and fluorescence detector," Journal of the Brazilian Chemical Society, vol. 29, pp. 24-32, 2018.

[60] X. He, G. N. Wang, K. Yang, H. Z. Liu, X. J. Wu, and J. P. Wang, "Magnetic graphene dispersive solid phase extraction combining high performance liquid chromatography for determination of fluoroquinolones in foods," Food Chemistry, vol. 221, pp. 1226-1231, 2017.

[61] G. N. Wang, K. Yang, H. Z. Liu, M. X. Feng, and J. P. Wang, "Molecularly imprinted polymer-based solid phase extraction combined high performance liquid chromatography for determination of fluoroquinolones in milk," Analytical Methods, vol. 8, no. 27, pp. 5511-5518, 2016.

[62] H. L. de Oliveira, S. da Silva Anacleto, A. T. M. da Silva et al., "Molecularly imprinted pipette-tip solid phase extraction for selective determination of fluoroquinolones in human urine using HPLC-DAD," Journal of Chromatography B, vol. 10331034, pp. 27-39, 2016.
[63] S. K. Motwani, S. Chopra, F. J. Ahmad, and R. K. Khar, "Validated spectrophotometric methods for the estimation of moxifloxacin in bulk and pharmaceutical formulations," Spectrochimica Acta Part A: Molecular and Biomolecular Spectroscopy, vol. 68, no. 2, pp. 250-256, 2007.

[64] A. Espinosa-Mansilla, "Partial least squares multicomponent fluorimetric determination of fluoroquinolones in human urine samples,” Talanta, vol. 62, no. 4, pp. 853-860, 2004.

[65] L. M. Du, Y. Q. Yang, and Q. M. Wang, "Spectrofluorometric determination of certain quinolone through charge transfer complex formation," Analytica Chimica Acta, vol. 516, no. 12, pp. 237-243, 2004.

[66] J. A. O. González, M. C. Mochón, and F. J. B. de la Rosa, "Spectrofluorimetric determination of levofloxacin in tablets, human urine and serum," Talanta, vol. 52, no. 6, pp. 1149$1156,2000$.

[67] J. A. Ocaña, F. J. Barragán, and M. Callejón, "Spectrofluorimetric determination of moxifloxacin in tablets, human urine and serum," The Analyst, vol. 125, no. 12, pp. 2322-2325, 2000.

[68] J. Shah, "Micellar-enhanced spectrofluorometric quantification of moxifloxacin in pharmaceutical formulations, human urine and plasma samples," African Journal of Pharmacy and Pharmacology, vol. 5, no. 5, pp. 616-624, 2011.

[69] D. González-Gómez, F. Cañada-Cañada, A. D. Campiglia, A. Espinosa-Mansilla, A. Muñoz de la Peña, and J. S. Jeong, "Rapid ultrasensitive chemometrics-fluorescence methodology to quantify fluoroquinolones antibiotics residues in surface water," Journal of Water Chemistry and Technology, vol. 38 , no. 5 , pp. $280-286,2016$.

[70] S. T. Ulu, "Spectrofluorimetric determination of fluoroquinolones in pharmaceutical preparations," Spectrochimica Acta Part A: Molecular and Biomolecular Spectroscopy, vol. 72, no. 1, pp. 138-143, 2009.

[71] S.-N. Yin, T. Yao, T.-H. Wu, Y. Zhang, and P. Wang, "Novel metal nanoparticle-enhanced fluorescence for determination of trace amounts of fluoroquinolone in aqueous solutions," Talanta, vol. 174, pp. 14-20, 2017.

[72] T. Yao, "Determination of trace fluoroquinolones in water solutions and in medicinal preparations by conventional and synchronous fluorescence spectrometry," Open Chemistry, vol. 16, no. 1, pp. 1122-1128, 2018.

[73] Z. Zhang, M. Zhang, X.-y. Wu et al., "Upconversion fluorescence resonance energy transfer-a novel approach for sensitive detection of fluoroquinolones in water samples," Microchemical Journal, vol. 124, pp. 181-187, 2016.

[74] H.-W. Sun, L.-Q. Li, and X.-Y. Chen, "Flow-injection enhanced chemiluminescence method for determination of ciprofloxacin in pharmaceutical preparations and biological fluids," Analytical and Bioanalytical Chemistry, vol. 384, no. 6, pp. 1314-1319, 2006.

[75] Z. Zhang, X. Li, X. Wang, S. Chen, B. Song, and H. Zhao, "Determination of ciprofloxacin by flow injection analysis based on chemiluminescence system," Journal of Rare Earths, vol. 24, no. 3, pp. 285-288, 2006.

[76] Y.-D. Liang, J.-F. Song, and X.-F. Yang, "Flow-injection chemiluminescence determination of fluoroquinolones by enhancement of weak chemiluminescence from peroxynitrous acid," Analytica Chimica Acta, vol. 510, no. 1, pp. 21-28, 2004.

[77] F. Aly, S. A. Al-Tamimi, and A. A. Alwarthan, "Chemiluminescence determination of some fluoroquinolone derivatives in pharmaceutical formulations and biological fluids 
using [Ru(bipy)32+]âCe(IV) system," Talanta, vol. 53, no. 4, pp. 885-893, 2001.

[78] J. A. Ocaña, F. J. Barragán, M. Callejón, and F. D. 1. Rosa, "Application of lanthanide-sensitised chemiluminescence to the determination of levofloxacin, moxifloxacin and trovafloxacin in tablets," Microchimica Acta, vol. 144, no. 1-3, pp. 207-213, 2004.

[79] J. A. Ocaña, M. Callejón, and F. J. Barragán, “Terbium-sensitized luminescence determination of levofloxacin in tablets and human urine and serum," The Analyst, vol. 125, no. 10, pp. 1851-1854, 2000.

[80] A. Navalón, O Ballesteros, R Blanc, and J. L Vílchez, "Determination of ciprofloxacin in human urine and serum samples by solid-phase spectrofluorimetry," Talanta, vol. 52, no. 52, pp. 845-852, 2000.

[81] O. Ballesteros, J. L. V'ilchez, and A. Navalón, "Determination of the antibacterial ofloxacin in human urine and serum samples by solid-phase spectrofluorimetry," Journal of Pharmaceutical and Biomedical Analysis, vol. 30, no. 4, pp. 1103-1110, 2002.

[82] H.-w. Sun, P. He, Y.-k. Lv, and S.-x. Liang, "Effective separation and simultaneous determination of seven fluoroquinolones by capillary electrophoresis with diode-array detector," Journal of Chromatography B, vol. 852, no. 1-2, pp. 145-151, 2007.

[83] M. Hernández, F. Borrull, and M. Calull, "Determination of quinolones in plasma samples by capillary electrophoresis using solid-phase extraction," Journal of Chromatography B: Biomedical Sciences and Applications, vol. 742, no. 2, pp. 255-265, 2000.

[84] H. Wang, Y. Liu, S. Wei, S. Yao, J. Zhang, and H. Huang, "Selective extraction and determination of fluoroquinolones in bovine milk samples with montmorillonite magnetic molecularly imprinted polymers and capillary electrophoresis," Analytical and Bioanalytical Chemistry, vol. 408, no. 2, pp. 589-598, 2016.

[85] K. Mitani and H. Kataoka, "Determination of fluoroquinolones in environmental waters by in-tube solid-phase microextraction coupled with liquid chromatography-tandem mass spectrometry," Analytica Chimica Acta, vol. 562, no. 1, pp. 16-22, 2006.

[86] M. Gao, H. Wang, M. Ma et al., "Optimization of a phase separation based magnetic-stirring salt-induced liquid-liquid microextraction method for determination of fluoroquinolones in food," Food Chemistry, vol. 175, pp. 181-188, 2015.

[87] R. İnam, H. Mercan, E. Y1lmaz, and B. Uslu, "Differential pulse polarographic determination of moxifloxacin hydrochloride in pharmaceuticals and biological fluids," Analytical Letters, vol. 40, no. 3, pp. 529-546, 2007.

[88] P. Lavaee, N. M. Danesh, M. Ramezani, K. Abnous, and S. M. Taghdisi, "Colorimetric aptamer based assay for the determination of fluoroquinolones by triggering the reduction-catalyzing activity of gold nanoparticles," Microchimica Acta, vol. 184, no. 7, pp. 2039-2045, 2017.

[89] E. Turiel, A. Martín-Esteban, and J. L. Tadeo, "Multiresidue analysis of quinolones and fluoroquinolones in soil by ultrasonic-assisted extraction in small columns and HPLCUV," Analytica Chimica Acta, vol. 562, no. 1, pp. 30-35, 2006.

[90] M. J. Schneider, S. E. Braden, I. Reyes-Herrera, and D. J. Donoghue, "Simultaneous determination of fluoroquinolones and tetracyclines in chicken muscle using HPLC with fluorescence detection," Journal of Chromatography B, vol. 846, no. 1-2, pp. 8-13, 2007.
[91] V. D’Angelo, F. Tessari, G. Bellagamba et al., "Microextraction by packed sorbent and HPLC-PDA quantification of multiple anti-inflammatory drugs and fluoroquinolones in human plasma and urine," Journal of Enzyme Inhibition and Medicinal Chemistry, vol. 31, no. sup3, pp. 110-116, 2016.

[92] M. Sturini, A. Speltini, L. Pretali, E. Fasani, and A. Profumo, "Solid-phase extraction and HPLC determination of fluoroquinolones in surface waters," Journal of Separation Science, vol. 32, no. 17, pp. 3020-3028, 2009. 